\title{
Experiences on the administration of botulinum toxin in movement disorders
}

\author{
Buket Tuğan Yıldız, Deniz Tuncel Berktaş \\ Kahramanmaraş Sütçü İmam University, School of Medicine, Department of Neurology, \\ Kahramanmaraş, Turkey
}

Address for Correspondence: Dr. Buket Tuğan Yıldız, Kahramanmaraş Sütçü Imam University, School of Medicine, Department of Neurology,

Kahramanmaras, Turkey.

E-mail: bukettugan@yahoo.com

\begin{tabular}{|l|}
\hline Access this article online \\
\hline $\begin{array}{l}\text { Website: } \\
\text { www.intern-med.com }\end{array}$ \\
\hline $\begin{array}{l}\text { DOI: } \\
\text { 10.2478/jim-2021-0003 }\end{array}$ \\
\hline Quick Response Code: \\
\hline \\
\\
\\
\\
\end{tabular}

\section{ABSTRACT}

Background and objectives: Botulinum toxin injection has been used for many years for various indications such as cervical dystonia, blepharospasm, oromandibular dystonia, hemifacial spasm in neurology. Botulinum toxin injections have been made in our clinic for about ten years. We want to report our experiences about botulinum toxin treatment in neurologic disease. Methods: In this study, the data of the patients receiving BoNT injection between January 2018 and December 2019 was retrospectively analyzed. Age, gender, botulinum toxin indications, and mean dose, duration of efficacy, side effects noted for each injection were recorded. Results: There were 122 patients who received botulinum toxin injections between January 2018 and December 2019. Of the 122 patients identified, 28 had cervical dystonia, 61 had HFS, 21 had blepharospasm, 4 had generalized dystonia, 1 had hemidystonia following thalamic bleeding, 1 had tardive dystonia, 4 had migraine, 1 had bruxism and 1 had both migraine and bruxism. Conclusion: BoNT injection is a treatment that has been used for various indications in neurology for almost 40 years. Side effects are limited and temporary with appropriate injections. We also had a wide range of indication profiles and high numbers of patients to whom we administered the BoNT treatment.

Key words: neurology, botulinum toxin injections, indications

\section{INTRODUCTION}

Botulinum toxin (BoNT) is a neurotoxin produced by Clostridium Botulinum, a gram-positive anaerobic bacterium, that we currently use in the treatment of $A$ and $B$ types. It was approved by the FDA (Food and Drug Administration) in 1989 for strabismus, blepharospasm, and hemifacial spasm (HFS) following the first administration in the treatment of strabismus in humans in 1980. When the BoNT-type A is injected into a muscle, it is taken up into a cell through endocytosis from the presynaptic nerve end at the neuromuscular junction. It inhibits the release of acetylcholine affecting fusion proteins; this chemical denervation leads to a relaxed paralysis in muscle. The effect of BoNT injection is at its peak in 2 weeks, lasts for an average of 3 months, and complete recovery occurs following a total reinnervation in 6 months. Injections at high doses and at short intervals lead to antibody development; therefore, they should be avoided. The applications of BoNT injections in neurology are varied. It can be administered in dystonia (focal hand dystonia, segmental dystonia, cervical dystonia, blepharospasm, oromandibular dystonia), spasticity, hemifacial spasm and tremor. $^{[1,2]}$

Blepharospasm is a focal dystonia of the orbital and periorbital muscles. The mean age of onset was reported to be 55.8 years, and the clinical presentation is observed after the age of 50 in most cases. ${ }^{[3,4]}$ Clinical manifestation of blepharospasm is usually involuntary blinking, and it gradually turns into involuntary dystonic contraction of the orbicularis oculi muscle. It may spread to the nasal, corrugator, and frontal muscles. These involuntary contractions may lead to functional blindness in the following periods. ${ }^{[4]}$ 
HFS is an involuntary, rhythmical, tonic or clonic movement disorder, which is derived from facial nerve root and occurs in unilateral facial muscles at intervals. Contractions occur firstly on the upper side of the face, which is orbicularis oculi, and spread to the perinasal, perioral muscles, and even to the platysma muscle over time. ${ }^{[5]}$ BoNT-type A injection had got ahead of the medical treatment with carbamazepine, benzodiazepine, and baclofen. ${ }^{[6]}$

Cervical dystonia is the most common type of focal dystonia. It is characterized by continuous or intermittent involuntary contractions of cervical muscles. This causes repetitive rotating motion of the head, neck, and shoulder, as well as painful and disabling abnormal posture..$^{[7,8]}$

Another group of patients into whom we injected BoNT is chronic migraine patients. It is considered that nociceptive fibers inhibit peripheral sensitization and reduce central sensitization, except local muscle paralysis caused by BoNT in chronic migraine. There are studies showing that BoNT-type A inhibits glutamate A, which are released from activated sensory nerve terminals and are important mediators of inflammatory pain as well as calcitonin generelated peptide, and substance P. ${ }^{[9-11]}$

It is suggested that the inhibition of these neurotransmitters helps reduce the amount of pain signals from the periphery to the central nervous system by preventing neurogenic inflammation and peripheral sensitization. ${ }^{[12]}$

\section{PATIENTS AND METHODS}

BoNT-type A injections have been administered for 10 years in the Department of Neurology, Faculty of Medicine, Kahramanmaraş Sütçü Imam University. In this study, the data of the patients receiving BoNT injection between January 2018 and December 2019 was retrospectively analyzed. Age, gender, botulinum toxin indications, and mean dose, duration of efficacy, side effects noted for each injection were recorded. Each vial was diluted with $2 \mathrm{~mL} 0.9 \% \mathrm{NaCl}$ for HFS, blepharospasm, migraine and bruxism, and with $1 \mathrm{~mL} 0.9 \% \mathrm{NaCl}$ for cervical dystonia, spasticity, and oromandibular dystonia.

Eye injections were administered into the medial and lateral orbicularis oculi muscle in the pretarsal area on the upper eyelid, and into the lateral orbicularis oculi muscle in the pretarsal area on the lower eyelid. The starting dose of the initial injections was $2.5 \mathrm{U}$ for each area, and subsequently, the dose was increased up to $5 \mathrm{U}$ if required by the clinical condition of the patient. The injections were administered under EMG guidance in cervical dystonia, bruxism, spasticity, and oromandibular dystonia. The starting dose for each injection area was $5 \mathrm{U}$. The dose was adjusted according to the clinical condition of the patient. A maximum dose of $20 \mathrm{U}$ of BoNT injection was administered into each injection area, and the total amount of dose injected in one session was not above $300 \mathrm{U}$. In patients with generalized dystonia and tardive dystonia, the injection was administered into the affected muscles at doses not exceeding $300 \mathrm{U}$ by evaluating the clinical condition of the patients. In chronic migraine patients, injections were administered into one point of the procerus muscle, two points of the corrugator supercilia muscle, and four points of the frontalis muscle. The starting dose of injections was $2.5 \mathrm{U}$ of botulinum toxin for each point, and it was increased up to $5 \mathrm{U}$ when required. Injections were administered into 4 points of the temporal muscles starting at a dose of $10 \mathrm{U}$, and the dose was increased up to $20 \mathrm{U}$ when required. Injections were administered into six points of the occipital area, four points of the cervical paraspinal area, and six points of the trapezius muscle at a dose of $10 \mathrm{U}$ for each point. The maximum dose was 200 $\mathrm{U}$ for all the patients. In tardive dystonia, hemidystonia, generalized dystonia, BoNT-A injections were administered into the active muscles at a dose of $10 \mathrm{U}$ for each injection point, not exceeding $300 \mathrm{U}$ in total.

\section{RESULTS}

A total of 122 patients who received botulinum toxin injections, between January 2018 and December 2019, were determined. Of the 122 patients identified, 28 had cervical dystonia, 61 had HFS, 21 had blepharospasm, 4 had generalized dystonia, 1 had hemidystonia following thalamic bleeding, 1 had tardive dystonia, 4 had migraine, 1 had bruxism, and 1 had both migraine and bruxism. The demographical characteristics of the patients regarding botulinum toxin indications are shown in Table 1 .

\section{Hemifacial spasm}

Of the 61 HFS patients, 32 were female and 29 were male. The age range was 35-90 years (mean: 63 years). The mean dose was 17.01 U BoNT. The mean duration of clinical effect following injections was 6.1 days. HFS developed after facial paralysis in four patients. There was no finding to suggest the development of secondary HFS in the history and the imaging of the patients. One patient had a bilateral HFS. Injection was administered into both sides. The dose of injections did not exceed $30 \mathrm{U}$ in any of the patients, except the patient with bilateral HFS. The frequency of injections was 128 days. In one patient, ptosis developed on the $5^{\text {th }}$ day following the injection and improved after 28 days. In one patient, injections of $1 \mathrm{U}$ each were administered into three points of the platysma muscle due to the contraction in the platysma muscle. 


\begin{tabular}{lllll}
\hline \multicolumn{6}{l}{ Table 1: The Characteristics of the Patients Receiving Botulinum A Injection } \\
\hline DISEASE & Number (M/F) & Age (Mean, yr) & Mean dose (U) & Injection frequency (days) \\
\hline Hemifacial spasm & $61(29 / 32)$ & $35-90(63)$ & 17 & 128 \\
Blepherospasm & $21(12 / 9)$ & $41-84(65.5)$ & 25,7 & 95 \\
Cervical dystonia & $28(15 / 13)$ & $20-79(49)$ & 220 & 110 \\
Generalized dystonia & $4(3 / 1)$ & $26-55(39)$ & 300 & 94 \\
Hemidystonia & $1 \mathrm{E}$ & 56 & 200 & 112 \\
Tardive dystonia & $1 \mathrm{E}$ & 45 & 300 & 125 \\
Migraine & $5 \mathrm{~K}$ & $23-46(35)$ & 158 & 134 \\
Bruxism & $1 \mathrm{~K}$ & 42 & 25 & \\
Migraine + Bruxism & $1 \mathrm{~K}$ & 32 & &
\end{tabular}

*The dose and frequency of BoNT injection for migraine + bruxism patients were included in the data of the patients with migraine.

\section{Blepharospasm}

Of the 21 blepharospasm patients, 9 were female and the age range of all patients was $41-84$ years (mean: 65.5 years). The mean dose was $25.7 \mathrm{U}$ BoNT. The frequency of injections was 95 days, and no complications developed in any of the patients.

\section{Cervical dystonia}

There were 28 patients with cervical dystonia who were followed up in our BoNT injection outpatient clinic during two years of follow-up. The age range was 20-79 years (mean: 48.8 years), 13 were women, and 15 were men. The amount of BoNT administered was mean $220 \mathrm{U}$. The maximum dose level was $300 \mathrm{U}$ for all patients. The mean frequency of injections for all patients was 110 days. One patient had mild dysphagia developed on the $4^{\text {th }}$ day following the injection and improved 20 days after the injection, and there were no other complications developed.

\section{Generalized dystonia}

The age range of four patients given BoNT injections was 26-55 years (mean: 38.7 years). Three were male and one was female. The dose was $300 \mathrm{U}$ for each BoNT injection in each patient. The patients applied to the clinic on an average of 94 days.

\section{Hemidystonia}

Injections of $200 \mathrm{U}$ for each session were administered to a 56-year-old male patient due to hemidystonia, which developed following thalamic bleeding. The patient applied to the outpatient clinic for an injection in mean every 112 days.

\section{Tardive dystonia}

Injections of $300 \mathrm{U}$ for each session were administered into the cervical and thoracic paraspinal areas in a 45-year-old male patient who was followed-up and treated with chronic psychosis diagnosis. The frequency of injections was 97 days.

\section{Chronic migraine}

The age range of five female patients followed-up with the diagnosis of chronic migraine and receiving an injection in mean every 125 days was $23-46$ years (mean: 35 years). The mean dose of botulinum toxin administered was 158 U. Of these patients, a 32-year-old female patient also had bruxism; therefore, she received additional injections into the masseter muscles.

\section{Bruxism}

In this indication, there was a 42 -year-old female patient receiving an injection. Moreover, a 32-year-old patient had both bruxism and migraine. The mean dose of BoNT injected was $25 \mathrm{U}$. The frequency of injections was 134 days.

\section{DISCUSSION}

In neurology, botulinum toxin injection is commonly used in focal dystonia such as blepharospasm, cervical dystonia, oromandibular dystonia, extremity dystonia, hemifacial spasm, spasticity, and migraine and it is a highly effective treatment.

After the first administration of BoNT by Scott in the treatment of strabismus in 1981, it was used for various functional and cosmetic indications. ${ }^{[13]}$ Kollewe et al. followed 133 patients with HFS and facial synkinesis for six years to compare the effects of Onabotulinum toxin $\mathrm{A}$ and Abobotulinum toxin A. BoNT injection took its therapeutic effect after mean 7.1 days and continued for 12.5 weeks. A total of $85 \%$ of the patients were stable during the monitoring, and side effects occurred in 5.4\% of the injections. ${ }^{[14]}$ 
Bentivoglio et al. evaluated 108 patients who received BoNT in the last ten years regarding the efficacy of Onabotulinum toxin $\mathrm{A}$ and Abobotulinum toxin $\mathrm{A}$ injection. The demographic data presented were as follows; of the 108 patients, $37(34.2 \%)$ were male and 71 were female, 20 $(18.5 \%)$ had facial paralysis. The mean age was 65.4 years and the mean dose of Ondabotulinum toxin was $11.2 \mathrm{U}$. Onabotulinum toxin took its clinical effect in 5.4 days, the duration of clinical effect was 85.4 days. A total of $16.7 \%$ of the patients had side effects. ${ }^{[15]}$

In the present study, most of the patients were women; however, there was no difference between the number of women and men in the patient group, as in the study by Bentivoglio et al. The mean age and mean dose of Onabotulinum administered to each patient for each injection were similar to the same study. The clinical effect after botulinum toxin injection was observed in 7.1 days in the patient population of the study by Kollewe et al., in 5.4 days in that of the study by Bentivoglio et al., and in 6.1 days in that of the present study. Similarly, the duration of the clinical effect was 12.5 weeks in the study by Kollewe et al. and 85.4 days in the study by Bentivoglio et al. As the patients in our study could not clearly state the duration of clinical effect, the duration of clinical effect could not be calculated exactly from the patient records; however, the mean time of applying to the outpatient clinic by the patients for injections was 128 days.

Lee et al. ${ }^{[16]}$ reported the demographical data of 101 patients with blepharospasm applying to their hospital for about two years. Of the 101 patients, 78 (77.2\%) were women and the mean age was 64.9 years. Aquino et al. ${ }^{[17]}$ identified 125 patients ( $75 \%$ women) after evaluating their 17 -year clinical data. The mean age was 54.3 years, and the mean duration of the effect of the toxin was 3.1 months. In the present study, there were 21 patients with blepharospasm, and the population mainly consisted of males, contrary to the study population of Lee and Aquino. The mean age of the patients was similar. The duration of the efficacy of toxin was similar between the study populations of both studies, and the duration of applying to the outpatient clinic for injection was similar to our study population (the duration of effect may be considered similar).

LeDovix et al. ${ }^{[18]}$ evaluated a total of 1000 cases with cervical dystonia in their study on genetics. The study population consisted mostly of women (750 women, 250 men) and the mean age was 60.2 years. In their prospective observational study, Jankovic et al. ${ }^{[11]}$ showed that the mean age of 1041 patients was 58.0 years, 774 were female $(74.4 \%)$, the mean dose of Onabotulinum toxin was $189 \mathrm{U}$, and the mean frequency of injection was 14.6 weeks. The mean age of 28 patients with cervical dystonia in the present study was lower than that of the study population of Jankovic and LeDovix (48.8 years). Unlike their study population, there were more men in the present study. The average amount of Onabotulinum toxin administered in this study was higher than that administered in the study by Jankovic et al. (220 and $189 \mathrm{U}$, respectively). The frequency of injections was 14.6 weeks in the study by Jankovic et al., while the mean duration was 110 days in our study.

In PREEMPT studies, it was proven that prophylactic BoNT injection was an effective and safe treatment option for migraine. ${ }^{[20,21]}$ The use of this treatment in migraine was approved by the FDA in the United States in 2010 and by the Ministry of Health in Turkey in 2011. Ilgaz Aydinlar et al. conducted a study on a study population consisting of 28 female and 2 male migraine patients with a mean age of 39.5 years. They administered BoNT-type A injection at a dose of $155 \mathrm{U}$ in every 12 weeks to each patient. The age range of five female patients in our study, followed up with the diagnosis of chronic migraine and receiving one injection in mean every 125 days, was $23-46$ years (mean: 35 years). The mean dose of BoNT administered was 158 U. As in the study by Ilgaz Aydinlar et al., we also used the injection sites indicated in PREEMPT study. The mean age and amount of injection were also similar. Migraine pain of the patient did not disappear with only one injection. When the patient reapplied to the outpatient clinic after a month due to pain, prophylactic propranolol was administered for 2 months. After three months, the injection was repeated, and propranolol was discontinued. The pain experienced by the patient disappeared.

In conclusion, BoNT injection is a treatment that has been used for various indications in neurology for almost 40 years. Side effects are limited and temporary with appropriate injections. We also had a wide range of indication profiles and high numbers of patients to whom we administered the BoNT treatment.

\section{Conflicts of Interest}

The authors declare that they have no conflict of interest.

\section{Source of Foundation}

The authors declare that this study has received no financial support.

\section{REFERENCES}

1. Matur Z, Parman Y. Botulinum toksininin nörolojide kullanım alanları. Klinik Gelişim 2010; 23: 121-7.

2. Türker H, Onar M, Demir O, Tunalı G. Ondokuz Mayıs Üniversitesi Nöroloji Kliniğinde Botulinum Toksin Uygulamaları: Retrospektif Bir Çalışma. O. M. Ü. Tip Derg 2007; 24: 6-14. 
3. Cardoso F, Jankovic J. Blepharospasm. Handbook of dystonia. Marcel Dekker 1995: 129-41.

4. Çakmur R. Botulinum Toxin Treatment of Blepharospasm and Hemifacial Spasm. Arch Neuropsychiatry 2010; 47: 6-10.

5. Chaudhry N, Srivastava A, Joshi L. Hemifacial spasm: The past, present and future. J Neurol Sci 2015; 356: 27-31.

6. Parman $Y$, Matur Z. Botulinum toksini ile ekstremite uygulamaları. Nöropsikiyatri Arşivi 2006; 43: 20-23.

7. Misra VP, Danchenko N, Maisonobe P, Lundkvist J, Hunger M. Economic evaluation of AbobotulinumtoxinA vs. OnabotulinumtoxinA in real-life clinical management of cervical dystonia. J Clin Mov Disord 2020; 7: 3-10.

8. Chan J, Brin MF, Fahn S. Idiopathic cervical dystonia: clinical characteristics. Mov Disord 1991; 6: 119-26.

9. Cui M, Khanijou S, Rubino J, Aoki KR. Subcutaneous administration of botulinum toxin A reduces formalin-induced pain. Pain 2004; 107: 125-33.

10. Meng J, Wang J, Lawrence G, Dolly JO. Synaptobrevin I mediates exocytosis of CGRP from sensory neurons and inhibition by botulinum toxins reflects their anti-nociceptive potential. J Cell Sci 2007; 120: 2864-74.

11. Gazerani P, Pedersen NS, Staahl C, Drewes AM, Arendt-Nielsen L. Subcutaneous Botulinum toxin type A reduces capsaicin-induced trigeminal pain and vasomotor reactions in human skin. Pain 2009; 141 : 60-9.

12. Aydinlar EI, Dikmen PY, Sağduyu A. Botulinum Toxin in Migraine Treatment. Arch Neuropsychiatry 2013; 50: 36-40.

13. Scott AB. Botulinum toxin injection of eye muscles to correct strabismus. Trans Am Ophthalmol Soc 1981; 79: 734-70.

14. Kollewe K, Mohammadi B, Dengler R, Dressler D. Hemifacial spasm and reinnervation synkinesias: long-term treatment with either Botox or Dysport. J Neural Transm (Vienna) 2010; 117: 759-63.
15. Bentivoglio AR, Fasano A, Ialongo T, Soleti F, Lo Fermo S, Albanese A. Outcome predictors, efficacy and safety of Botox and Dysport in the long-term treatment of hemifacial spasm. Eur J Neurol 2009; 16: 392-8.

16. Lee JM, Baek JS, Choi HS, Kim SJ, Jang JW. Clinical Features of Benign Essential Blepharospasm in Korean Patients. Korean J Ophthalmol 2018; 32: $339-43$.

17. Aquino CC, Felício AC, Castro PC, Oliveira RA, Silva SM, Borges V, et al. Clinical features and treatment with botulinum toxin in blepharospasm: a 17-year experience. Arq Neuropsiquiatr 2012; 70: 662-6.

18. LeDoux MS, Vemula SR, Xiao J, Thompson MM, Perlmutter JS, Wright LJ, et al. Clinical and genetic features of cervical dystonia in a large multicenter cohort. Neurol Genet 2016; 2: e69.

19. Jankovic J, Adler CH, Charles D, Comella C, Stacy M, Schwartz M, et al. Primary results from the cervical dystonia patient registry for observation of onabotulinumtoxina efficacy (CD PROBE). J Neurol Sci 2015; 349: 84-93.

20. Aurora SK, Dodick DW, Turkel CC, DeGryse RE, Silberstein SD, Lipton RB, et al. PREEMPT 1 Chronic Migraine Study Group. Onabotulinumtoxin A for treatment of chronic migraine: Results from the double-blind, randomized, placebo-controlled phase of the PREEMPT 1 trial. Cephalalgia 2010; 30: 793-803.

21. Diener HC, Dodick DW, Aurora SK, Turkel CC, DeGryse RE, Lipton RB, et al. PREEMPT 2 Chronic Migraine Study Group. Onabotulinumtoxin A for treatment of chronic migraine: Results from the double-blind, randomized, placebo-controlled phase of the PREEMPT 2 trial. Cephalalgia 2010; 30: 804-14.

How to cite this article: Tuğan Yıldız B, Tuncel Berktaş D. Experiences on the administration of botulinum toxin in movement disorder. J TransI Intern Med 2021; 9: 52-6. 